WSRC-RP-92-578

DE93003384

\title{
An Overview of Treatment and Characterization Technologies for Environmental Remediation at the Savannah River Site (u)
}

D. L. Holt

B. T. Butcher

Westinghouse Savannah River Company Savannah River Site Aiken, SC 29808

Authorized Derivative Classifier

in. a abra 4/30/92

M. A. Ebra, Manager

Environmental Restoration Technology 


\section{DISCLAIMER}

This report was prepared by Westinghouse Savannah River Company (WSRC) for the United States Department of Energy under Contract No. DE-AC09-89SR18035and is an account of work performed under that contract. Neither the United States Department of Energy, nor WSRC, nor any of their employees makes any warranty, expressed or implied, or assumes any legal liability or responsibility for the accuracy, completeness, or usefulness, of any information, apparatus, or product or process disclosed herein or represents that its use will not infringe privately owned rights. Reference herein to any specific commercial product, process, or service by trademark, name, manufacturer or otherwise does not necessariy constitute or imply endorsement, recommendation, or favoring of same by WSRC or by the United States Government or any agency thereof. The views and opinions of the av'hors expressed herein do not necessarily state or reflect those of the United States Government or any agency thereof.

Printed in the United States of America

Available from

National Technical Information Service

U. S. Department of Commerce

5285 Port Royal Road

Springfield, VA 22161 
WSRC-RP-92-578

$\underline{\text { Key Words }}$

Environmental Restoration

Technology Summary

Characterization

Treatment

Retention: Permanent

\section{An Overview of Treatment and Characterization Technologies for Environmental Remediation at the Savannah River Site (u)}

D. L. Holt

B. T. Butcher

Publication Date: May, 1992

Westinghouse Savannah River Company Savannah River Site Aiken, SC 29808

Authorized Derivative Classifier

m.9. 98 ra $4 / 30 / 92$

M. A. Ebra, Manager

Environmental Restoration Technology 


\title{
AN OVERVIEW OF TREATMENT AND CHARACTERIZATION TECHNOLOGIES FOR ENVIRONMENTAL REMEDIATION AT THE SAVANNAH RIVER SITE (u)
}

\author{
By D. L. Holt and B. T. Butcher \\ Westinghouse Savannah River Company \\ Savannah River Site \\ Aiken, SC 29808
}

\begin{abstract}
The Environmental Restoration Department (ERD) at the Savannah River Site (SRS) has the responsibility to remediate waste sites and groundwater to standards as determined by Federal and State Authorities. This mission requires that certain programmatic interfaces within the ERD, Savannah River Technology Center (SRTC, formerly Savannah River Laboratory (SRL)), the Department of Energy Headquarters (DOE-HQ) Office of Technology Development (OTD), and outside commercial contractors be utilized to ensure cost-effective remediation technologies are utilized. This paper provides a synopsis of a select cross-section of the treatment and characterization technologies currently being pursued by ERD. Environmental Restoration Technology (ERT) Department's future role in providing the necessary technologies for waste sites and groundwater remediation is also discussed.
\end{abstract}




\section{CONTENTS}

Introduction 1

ER Technology Program Interfaces 2

Table 1. Site Problem Unit Listing for Cruss-Referencing and

Treatment/Characterization Technology Status Indicators 5

Treatment Technologies 6

Figure 1. Graphical Representation of Treatment Technologies 7

In-Situ Treatment Technologies

i. In-Place In-Situ Treatment Technologies 8

Final Vegetation Coverage for Waste Site Closure Caps

Studies to Alter Groundwater Chemistry at Seepline

Cap Infiltration Studies

Barrier Material Test Plot

Closure Cap Barrier Materials Study

Lessons Learned from M-Area Basin Closure

Waste Stabilization via Dynamic Compaction

Waste Stabilization via Static Surcharge

Subsidence Repair of ER Closure Caps

Deep Soil Mixing and In-Situ Stabilization

In-Situ Bioremediation

ii. Removal In-Situ Treatment Technologies

In-Situ Mobilization of Metal Contaminants

Electrolytic Migration Technology

Horizontal Well Vapor Extraction

Radio Frequency Heating Demonstration

Ex-Situ Treatment Technologies 14

Off-Gas Treatment for VOCs

Bioremediation Technology for Organic Destruction

Bioremediation Treatment Regime for PAH from RR Crossties

Soil Washing/Low Temperature Thermal Study

Air Stripping for VOCs - Pump and Treat Method

Re-Injection of Treated Groundwater Studies

Recovery Well and Injection Well Pump Tests

Electrolytically Assisted Ion Exchange for Nitrates

Seeded Magnetic Filtration for Heavy Metals

Reverse Osmosis for Inorganic Removal 


\section{CONTENTS}

Matrix of Treatment Technologies versus Waste Sites 18,19

Characterization Technologies 20

Figure 2. Graphical Representation of Characterization Technologies _ 21

Above Surface Characterization Technologies 22

Vegetation, Fish, and Macroinvertebrate Sampling

Aerial Photography and Photogrammetry

Surface Unit Characterization Technology 24

Non-Intrusive Cap Integrity Monitoring

3-D Ground Penetration Radar

Ion Trap Mass Spectrophotometer

Subsurface-Unsaturated Zone Characterization Technologies 25

Lysimeters to Study and Monitor Radionuclide Migration in Soils

Soil Gas Measurements

Cone Penetrometer Measurements

Geophysical Techniques

$\mathrm{Hg}$ Speciation in Groundwater

Prompt Gamma Neutron Activation Analysis

Subsurface-Saturated Zone Characterization Technologies 28

Modeling Efforts for Plume Assessment

Stochastic Inverse Contaminant Flow and Transport Modeling

Tritium Dating of Aquifers to Determine Waste Water Penetration Depth

DNAPL Characterization and Assessment

Matrix of Characterization Technologies versus Waste Sites 30

Environmental Restoration Technology Future Role 31

Acknowledgements 32 


\section{INTRODUCTION}

The Environmental Restoration Department (ERD) is actively pursuing many different treatment and characterization technologies to address the 100 + identified waste sites on the Federal Facilities Agreement (FFA) list. The compilation of these technologies for use as a reference and orientation guide has been requested and this paper attempts to summarize the information in a format that is easily understood. The facilitation of this information has been accomplished by subdividing the treatment technologies into the following categories: in-place in-situ treatment technologies; removal in-situ treatment technologies; and ex-situ treatment technologies. The characterization technologies have been also been subdivided into the following categories: above surface; surface unit; subsurface-unsaturated zone; and subsurface-saturated zone. Additionally, the treatment and characterization technologies have been cross-linked and matrixed to site specific waste units (including groundwater) and further defined as available for use or under development for use at SRS.

The customer interfaces ERD utilizes to develop treatment and characterization technologies have also been examined. Technology development requires a very active interface program with many different internal and external organizations to meet the challenges for safe, cost-effective, and timely waste site restoration activities. The internal programmatic organizational interfaces within ERD are along the same organizational lines that the DOE utilizes. This facilitates direct contact with appropriate DOE departments. The technology exchange between DOE sites has been facilitated through the formation of a Technology Information Exchange (TIE) program which sponsors semi-annual meetings and publishes a quarterly newsletter relating to on-going environmental restoration activities. DOE-Office of Technology Development (OTD) provides technology development primarily through complex wide Integrated Demonstrations (ID) and funding for Research and Development Activities. ERD provides funding to Savannah River Technology Center (SRTC) to provide support for existing and emerging treatment and characterization technologies. The commercial environmental restoration activities provide an opportunity to examine field tested technologies and their applicability to SRS site specific problems. Programs also exist such as the Environmental Protection Agency's Superfund Innovative Technology Evaluation which allow for commercial vendors to demonstrate treatability technologies at designated Comprehensive Environmental Response, Compensation, and Liability Act (CERCLA) sites. 


\section{ER TECHNOLOGY PROGRAM INTERFACES}

\section{Internal Environmental Restoration}

Internal ER organizations are organized functionally according to the elements of a remedial action program similar to environmental restoration management contractors (ERMACs) at other DOE sites. ER Assessments (ERA) and ER Technology (ERT) are responsible for initial investigations, development of alternatives, and preparation of regulatory decision documents on waste sites and groundwater units, respectively. The ER Closures (ERC) section is responsible for implementing the regulatory decision document beginning with remedial design and construction followed by monitoring and maintenance. A task team approach is typically utilized to accomplish project objectives and maintain consistency through each stage of the remedial action process. Task team member charge their time to the project through the Consolidated Labor System.

Environmental Restoration Technology (ERT) is also responsible for facilitating development and delivery of technologies needed for each stage of the remedial action process. ERT professionals are assigned to facilitate specific technology areas. Advances are made in "state of the art" ER technologies when internal and external interfaces are successfully used to accomplish ER objectives.

\section{Savannah River Technology Center}

The Savannah River Technology Center plays a key role in researching and developing new ER technologies as well as providing hands on experience and knowledge of off-the-shelf technologies. Technology research and development is typically funded by the Office of Technology Development as part of the Integrated Demonstration (see below). SRTC provides technology support in many areas, notably; laboratory treatability studies, field demonstrations of groundwater remediation processes, groundwater flow and transport modeling, closure cap performance, closure cap monitoring and maintenance, ecological studies, subsurface investigations and process safety. SRTC interfaces with ER through their participation on project task teams as well as bi-monthly work reviews. SRTC budget priorities are established in the Annual Operating Plan. ER monies may be transferred to SRTC via Task Description Documents. Alternatively, SRTC activities may be charged against an ER service order.

\section{Office of Technology Development}

The technology integration/transfer occurs through the use of Technology Roadmaps for the SRS Integrated Demonstration (ID) for Organic Compound Removal in Non-Arid Soils. At present, the SRTC Groundwater Remediation Project Schedule, M-Area Vadose Zone Project Schedu'e, and Southern Sector Groundwater Remediation Project Schedule have been linked to the different technologies being developed at the the ID site. The schedules when coupled with abstracts of the different technologies (under development) will provide a powerful tool for ER and Systems Engineering professionals for design of remediation projects. Technology Roadmaps to other ER remediation sites will be constructed in the future as needed to guide the technology integration. 


\section{Wer tinghouse Corporate}

A number of new interfaces have recently been established with Westinghouse Corporate. The Westinghouse Science and Technology Center (S\&TC) chairs the Waste and Environmental Information Exchange Committee which provides a forum for discussion and a basis for business units benefitting each other through cooperation and awareness. WSRC is also represented on the Technology Council which provides direction to the Corporation on development of new technologies and markets. In a process sponsored by the Westinghouse GOCO Environmental Committee, WSRC-ER has been applying Cost/Time Management principles in identifying time and cost savings in the Remedial Investigation/Feasibility Study regulatory process. Finally, WSRC-ER recently utilized the Quality Productivity Center to help conduct a Total Qality Fitness Review.

Technology transfer between Westinghouse Corporate and Westinghouse GOCOs is arranged through an Internal Work Request (IWR), which is a sole source arrangement. As a general rule, a technology or service must be shown to be unique in order to have sole source access to Westinghouse Corporate technologies.

Currently, WSRC is working with the S\&TC to conduct bench-scale soil washing treatability studies on selected SRS soils. WSRC and the S\&TC are also working on a proposal to further develop prompt gamma neutron activation analysis (PGNAA) as a remote sensing technology for investigating process sewer lines, tanks and boreholes. A second propnsal for a benchscale treatability study using both soil washing and low temperature thermal desorption technologies has also recently been initiated.

\section{Commercial Vendors/Subcontractors}

WSRC-ER routinely utilizes commercial vendors providing speciality services and technologies to help accomplish various tasks associated with the remedial action process. This process has provided WSRC-ER access to new technologies not available in-house. These services span from initial site characterization to final monitoring and maintenance of a closed site. Notable services include sampling and analysis, geophysical measurements, well installation, groundwater modeling, feasibility studies, treatability studies, pilot-scale demonstrations, regulatory document preparation, remedial design, facility construction, and many more.

WSRC-ER has set up multi-year task order subcontracts with a group of consultants commonly known as the five-pack (Dames \& Moore, SAIC, Sirrine, Metcalf \& Eddy, and CDMFederal). These consultants provide speciality services typically in the areas of alternative/feasibility studies and regulatory document preparation. Task order subconiracts have also been established for groundwater sampling and analysis, soil-gas surveying and well drilling. Task assignments against these subcontracts can take as little as one month to put in place. Alternatively, individual subcontracts can be negotiated for one time only services. These subcontracts typically take between 6-8 months to place. 


\section{Government Contractors (GOCOs)}

A large amount of technical expertise resides within the DOE complex. Although the mission, history and setting of each DOE facility is unique, there are many common environmental issues shared by facilities. Many sites have historically utilized onsite disposal (shallow land burial, seepage basins, burning/rubble pits, etc.) in the management of their wastes resulting in radioactive, organic and inorganic contamination of surrounding media. Technical information exchange between sites is essential if cost effective assessment and cleanup technologies are tof be implemented. DOE has recognized the difficulty in arranging communications between its contractors on ER technology issues. To facilitate this interface, DOE has initiated bi-annual Technical Information Exchange (TIE) Workshops to be held around the Complex. The first TIE work shop was held in Augusta in 1991. WSRC-ER also participates with the Idaho National Engineering Laboratory on task teams supporting the Buried Waste Integrated Demonstration.

Regulatory policy set for one site or region can affect policy at other facilities. In addition, states hosting DOE facilities have begun networking and sharing information on issues of common interest (ex. Federal Facility Agreement terms). Savannah River and Oak Ridge share the same EPA regional office as well as common regulatory issues and concerns. SR/OR Environmental Restoration technical information exchanges were recently initiated to share information and help develop ccnsistent approaches with the regulators.

DOE Contractors can also do work for others. An example of this is WSRC-ERs use of Martin Marietta Energy Systems for human health risk assessment support. The mechanism for transferring funds between sites is Memorandum Purchase Order.

\section{Other}

Numerous other interfaces are important in facilitating development of technologies and exchange of information. DOE-ER is our primary customer and helps set ER objectives through the Award Fee process. A recent example of this has been the requirement to initiate partnerships with commercial vendors on emerging technologies through onsite, pilot-scale demonstration. DOE is provided technical support by the Core of Engireers.

Another important internal organization is the Engineering and Projects Division (E\&PD) which includes Westinghouse Systems Engineering (SE) department and Bectel Design and Construction. These organizations function in a matrix fashion to ER in providing technical/design baselines, engineering design, and construction services.

Regulators are also a source of information on ER technologies. The EPA maintains a Record of Decision (ROD) database which stores information on all RODs nationwide and the technologies selected for their implementation. The EPAs Superfund Innovative Technology Evaluation (SITE) Program seeks to encourage private sector development by firms that are willing to commercialize EPA-developed technologies for use at Superfund sites. 
Table 1. Site Problem Unit Listing for Cross-Referencing and Treatment/ Characterization Technology Status Indicators

\begin{tabular}{|c|c|}
\hline Abbreviation & Site Problem Unit \\
\hline $\mathrm{A} / \mathrm{CSB}$ & Acid/Caustic Seepage Basins \\
\hline AMGW & A/M Area Groundwater \\
\hline AMVZ & A/M Area Vadose Zone \\
\hline BRP & Burning Rubble Pits \\
\hline CPRB & Coal Pile Runoff Basins \\
\hline FHSB & F\&H Area Seepage Basins \\
\hline FHSB-GW & F\&H Area Seepage Basin Groundwater \\
\hline FHSBSL & F\&H Area Seepage Basin Process Sewer Line \\
\hline HLWTF-GW & High Level Waste Tank Farm Groundwater \\
\hline HLWTF-S & High Level Waste Tank Farm Soil \\
\hline LLWDF & Low Level Waste Disposal Facility \\
\hline LLWDF-GW & Low Level Waste Disposal Facility Groundwater \\
\hline MLSB & Met Lab Seepage Basin \\
\hline RASB & R-Area Seepage Basin \\
\hline RRCP & F-Area Railroad Crosstie Pile \\
\hline SL-GW & Sanitary Landfill Groundwater \\
\hline SL-S & Sanitary Landfill Soil \\
\hline SRLSB & SRL Seepage Basin \\
\hline TNXSB & TNX Seepage Basins \\
\hline TNXGW & TNX Groundwater \\
\hline
\end{tabular}

\begin{tabular}{cl} 
Abbreviation & Technology Status Indicator \\
\hline A\&D & Available and Demonstrated at SRS \\
AV & Available, Demonstration at SRS Needed or Underway \\
UD/IP & Under Development and/or Demonstration at SRS \\
& In-Progress
\end{tabular}




\section{TREATMENT TECHNOLOGIES}

ERT is actively pursuing many different treatment technologies for remediation purposes of identified waste sites at SRS. The treatment technologies have been grouped as given here-in.

\section{In-Situ Treatment Technologies:}

Technologies which directly address the contaminant without requiring the handling and associated treatment of the media in which the contaminant is contained.

There are two subcategories for In-Situ Treatment Technologies. These are:

\section{In-Place In-Situ Treatment Technologies:}

This technology treats the contaminant in-place and therefore does not require the removal of the contaminant for treatment. An example of this treatment technology is in-situ bioremediation where organisms degrade the contaminant into acceptable forms.

\section{Removal In-Situ Treatment Technologies:}

This technology treats the contaminant after it has been removed from the media in which it is located in. An example of this treatment technology is the vapor extraction of volatile organic compounds where the organics are removed from the soil by enhanced vaporization.

\section{Ex-Situ Treatment Technologies:}

Technologies which require the removal of both the contaminant and the media in which they are held to another location for treatment and contaminant removal. The media must also be handled in this treatment technology. An example of this treatment technology is soil washing where the soil is excavated, processed through several urit operations to remove the contaminant, and returned to the original excavation site or to another location.

A graphical representation of treatment technologies is given as Figure 1. This figure provides for a visual correlation between the technology and its application. The treatment technologies are then described per the above categories followed by a matrix of treatment technologies versus applicable waste sites. 
I

I

I

I

I

I

I

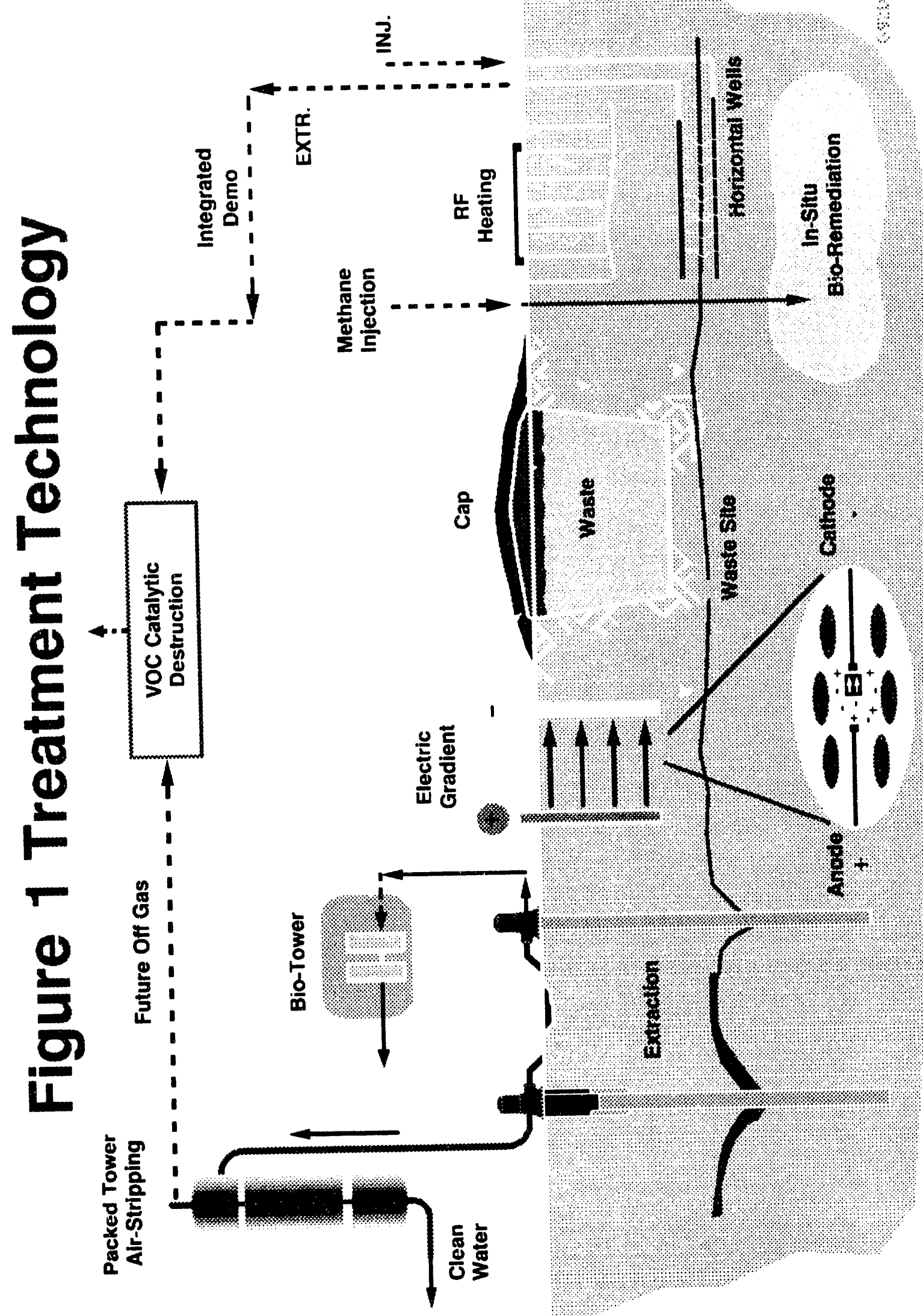

I

I

I

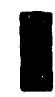

I

I 


\section{IN-PLACE IN-SITU TREATMENT TECHNOLOGIES}

- SRL-IWT, Final Vegetation Coverage for Waste Site Closure Cap

Site Applicability: Any Site Closed by Capping

Status \& Matrix ID: UD/IP; A1

A field study is being conducted to evaluate the effectiveness of different shallow root vegetation species for use on closure cover system. The vegetative cover of a cover system is to minimize erosion, maximize evapotranspiration, and to prevent the growth of deep rooted plants which can penetrate the entire cur system. The primary vegetation species being : valuated are bamboo and a variety of grasses.

- SRL-ESS, Studies to Alter Groundwater at Seepline Site Applicability: FHSB, LLWDF

Status \& Matrix ID: UD/IP; A2

The feasibility of in-situ treatment of the contaminant plume at the point of exposure, the seepline, will be investigated. As currently conceived, wells will be placed immediately upgradient from the seepline boundary. Limestone and/or gypsum will be injected through the wells to precipitate the contaminants. Multi-port lysimeters, placed upgradient and downgradient from the wells, will be used to monitor the changes in groundwater chemistry. Installation of the first test area is expected to be completed by late spring 1992 .

- SRL-IWT, Cap Infiltration Studies

Site Applicability: Any Site Closed by Capping

Status \& Matrix ID: UD/IP; A3

A field study is being conducted to measure the infiltration rates through typical closure cover system configurations. The data obtained will be used to validate the use of the ACE Hydrologic Evaluation for Landfill Performance (HELP) computer code for SRS conditions. The results of the study will be used to assess performance of existing closures and provide design parameters for future configurations. 


\section{ER, Barrier Material Test Plot}

Site Applicability: Any Site Closed by Capping

Status \& Matrix ID: UD/IP; A4

A field study to determine the hydraulic and subsidence performance characteristics of the available closure cover system barrier materials. Initially, the field study will examine the performance characteristics of a bentonite mat composite barrier system.

- ER, Closure Cap Barrier Materials Study

Site Applicability: Any Site Closed by Capping Status \& Matrix ID: A\&D; A5

A comprehensive study was conducted to categorize present waste sites and the characteristics of available barrier materials for closure cover systems. The results of the study provided recommended barrier material(s) considerations for each waste site category.

\section{ER, Lessons Learned from M-Area Basin Closure}

Site Applicability: Any Site Closed by Capping Status \& Matrix ID: A\&D; A6 The M-Area Basin Closure was one of the first waste site closures at SRS. This successful project has set the stage for future ER work. The lessons learned from this closure will provide a baseline for improvement of future waste site closure designs.

\section{ER, Waste Stabilization via Dynamic Compaction}

Site Applicability: LLWDF

Status \& Matrix ID: AV; A7

The anticipated method to stabilize Low Level Radioactive Waste Disposal Facility prior to closure is dynamic compaction. This effort will determine if dynamic compaction will adversely impact the existing Mixed Waste Management Facility kaolin clay cap. 


\section{- ER, Waste Stabilization via Static Surcharge}

Site Applicability: SL-S

Status \& Matrix ID: AV; A8

The Sanitary Landfill will be closed as a hazardous waste facility. The successful design and construction of a closure cap is dependent upon the minimization of damaging differential settlement. The static surcharge test will optimize the placement depth and duration of the actual surcharge during ciosure. The test will also provide waste characterizing engineering parameters in support of design efforts.

\section{ER, Subsidence Repair of ER Closure Caps}

Site Applicability: Any Site Closed by Capping Status \& Matrix ID: AV; A9

All closed waste sites at SRS have the potential to experience subsidence with time. Subsidence repair will be necessary to maintain the physical and regulatory integrity of the closed sites. Effective subsidence repair techniques can minimize closure cap damage and long term cost.

\section{- ER/ESS, Deep Soil Mixing and In-Situ Stabilization} Site Applicability: RASB, SRLSB

Status \& Matrix ID: AV; A10

Soils and basins contaminated with concentrations of mixed and radioactive wastes will require remedial actions that may involve stabilization in place. Deep soil mixing is a technology that enables the stabilization of fluids, sludge, and soils in-situ. Large augers mix the soil with grout and admixtures to bind the contaminants within a solid, soil cement mass. Potentially, highly contaminated sludge basins and underlying soils can be stabilized in-situ, minimizing direct contact and risk to the workers. 
- SRL-ID/ESS, In-Situ Bioremediation

Site Applicability: AMGW, AMVZ

Status \& Matrix ID: UD/IP; A11

Methane Gas and Air will be injected into the ground via a lower level horizontal well and a vacuum extraction will be pulled on the upper horizorital well. The methane gas and air injection will stimulate the growth of indigenous microorganisms to degrade TCE to harmless compounds. 


\title{
REMOVAL IN-SITU TREATMENT TECHNOLOGIES
}

\author{
SRL-IWT, In-Situ Mobilization of Metal Contaminants \\ Site Applicability: FHSB, FHSBSL, LLWDF \\ Status \& Matrix ID: UD/IP; B1 \\ The Savannah River Laboratory (SRL) in collaboration \\ with Clemson University are investigating in-situ \\ mobilization for remediation of metal contaminated sites. \\ The scope of the study includes identifying potential \\ complexing agents to mobilize sorbed contaninants in \\ soil. After screening and laboratory testing, the \\ technology will be demonstrated in the field using SRL \\ lysimeters. Initial work indicates that complexing agents \\ containing carboxylate groups such as Ethylene Diamine \\ Tetraacetic Acid (EDTA), are potential candidates. \\ However, iron may compete with the toxic metals and \\ radionuclides for the complexing agent.
}

- SRL-IWT, Electrolytic Migration Technology Site Applicability: FHSB, FHSB-GW, FHSBSL-GW, HLWTF-

Status \& Matrix ID: $\quad$ UD/IP; B2

Electrolytic migration causes ionic contaminants in groundwater or soils to migrate toward electrodes under an applied current. Metal ions are collected at the cathode using ion exchange resin impregnated polymer or an ion permeable polymer that allows collection of concentrate. Anions may be collected at the anode.

- SRL-ID/ESS, Horizontal Well Vapor Extraction Site Applicability: AMGW, AMVZ

Status \& Matrix ID: A\&D; B3

The primary advantages of horizontal wells relates to matching their geometry to the shape of a plume, accessing a thin subsurface layer, intercepting the leading edge of a plume, drilling beneath buildings, or protecting a linear feature such as a facility boundary. The advantages in terms of performance must off-set the increased drilling costs and complexity associated with installation to justify use of the technology. 


\section{- SRL-ID/ESS/ER, RF Heating Demonstration}

Site Applicability: AMVZ

Status \& Matrix ID: AV; B4

Radio frequency (RF) heating technology utilizes dielectric heating in conjunction with antenna technology to radiate electromagnetic energy to heat the material surrounding the antenna. RF heating causes heating at the molecular level, and is not limited by the surrounding materials heat transfer properties. Moist soils and hydrocarbon sludges are good examples of materials easily heated in this manner. RF heating is used to increase the efficiency of in-situ remediation systems for volatile and semivolatile organic contaminants. 


\title{
EX-SITU TREATMENT TECHNOLOGIES
}

\author{
SRL-ID, Off-Gas Treatment For VOCs \\ Site Applicability: AMGW, AMVZ, SRLSB, TNX-GW \\ Status \& Matrix ID: AV; C1 \\ Chlorinated volatile organic compounds are the most \\ pervasive subsurface contaminants within the DOE \\ Complex. Current remediation technologies for both soil \\ and groundwater produce a gas phase stream containing \\ VOCs. 1990 Amendments to the Clean Air Act have \\ elevated the need to develop effective technologies to \\ treat remediation system off-gases. This need has \\ motivated the development of new and diverse \\ technologies to include: free radical oxidation, carbon \\ regeneration, biodestruction, membrane separation, \\ thermal and catalytic oxidation, and Xenon flashlamp \\ destruction.
}

- SRL-ESS, Bioremediation Technology for Organic

\section{Destruction}

Site Applicability: AMGW, AMVZ, SL-GW, SRLSB, TNX-GW

Status \& Matrix ID: UD/IP; C2

Three different types of bioreactors will be tested on a pilot scale (1-3 gpm) with actual groundwater

contaminated with TCE. The bioreactors utilize a

continuous flow system to treat the groundwater. The

bioreactors are a trickle filter ceramic bed material type, fluidized expanded bed type, and a rotating contactor biological bed type. The microorganisms used will be cultured from SRS soils/water and methane gas will be used as a nutrient.

- SRL-ESS, Bioremediation Treatment Regime For PAH (polycyclic aromatic hydrocarbons) From RR Crossties, Site Applicability: RRCP

Status \& Matrix ID: AV; C3

Naturally occurring microorganisms have been found which will degrade PAH and their derivatives. The RR crossties would be ground-up and the organisms introduced and cultured. Experimental work to date has shown a 95\% reduction in contaminants in a four week digestion period. 


\section{SRL-IWT/ER/S\&TC, Soil Washing/Low Temperature}

Thermal Study

Site Applicability: Any Site Contaminated by Organics Status \& Matrix ID: UD/IP; C4

Soil Washing is an ex-situ Volume Reduction Unit that combines physicai and chemical processes to remove contamination from soil. Soil washing can be applied to both organic and heavy metal contamination. After the smaller soil particles are physically separated from the soil, these particles can then be chemically treated to remove the contamination by means of acids, bases, chelates, solvents, and surfactants.

Low Temperature Thermal Desorption (LTTD) is primarily used in treating soils contaminated with volatile and semi-volatile contaminants. LTTD is an ex-situ system that processes soil through a rotary drum equipped with heat transfer surfaces. Soils are heated to 500-800 oF. Organics with boiling points less than 800 oF are easily desorpted, while metals must be treated separately.

- ER, Air Stripping for VOCs - Pump and Treat Method Site Applicability: AMGW, SRLSB, TNXGW

Status \& Matrix ID: AV; C5

Air stripping is a technology used to trea: groundwater containing volatile organic compounds. The technology is currently being used at two locations within the $\mathrm{A} / \mathrm{M}$ Areas of the Site. Pump and treat with air stripping is used to remediate the areas of high contamination and to achieve hydraulic control of a plume. 
- SRL-ESS, Re-Injection of Treated Groundwater Studies Site Applicability: FHSB, FHSB-GW

Status \& Matrix ID: UD/IP; C6

Reinjection of the treated groundwater into the subsurface at $\mathrm{F} / \mathrm{H}$ Areas has the potential to disperse colloidal materials into the injection zone and result in clogging or possible failure of the injection wells. In order to determine the compositional limits of the reinjected water to minimize this potential problem, ESS will work with SREL to investigate the colloid properties of the injection zone with particular reference to the sodium adsorption ratios, and the effects of $\mathrm{pH}$ and ionic strength on colloid formation.

- ER, Recovery Well and Injection Well Pump Tests Site Applicability: FHSB, FHSB-GW

Status \& Matrix ID: UD/IP; C7

To gain a complete understanding of the aquifer parameters of each hydrogeologic unit to be remediated at $\mathrm{F} / \mathrm{H}$ Areas, aquifer pump tests are being performed in both aquifers. Pump tests are essential to obtain accurate aquifer parameters required in the development, design, and implementation of a Corrective Action Plan for groundwater remediation. Furthermore, obtaining representative aquifer parameters within the extraction and injection areas will avoid and/or eliminate misleading values introduced by anisotropic or heterogeneous conditions.

\section{SRL-IWT, Electrolytically Assisted Ion Exchange For} Nitrates

Site Applicability: FHSB-GW, HLWTF-GW, LLWDF-GW, TNXGW

Status \& Matrix ID: UD/IP; C8

Electrochemical ion exchange is a variation of the conventional ion exchange process. Ionic contaminants are removed from a waste stream by ion exchange while electrodialysis is used to continuously regenerate the ion exchange resin. The process provides the effectiveness of ion exchange and reduces the secondary waste associated with resin regeneration. 
- SRL-IWT, Seeded Magnetic Filtration for Heavy Metals Site Applicability: FHSB-GW, HLWTF-GW, LLWDF-GW Status \& Matrix ID: UD/IP; C9

Seeded magnetic filtration uses an applied magnetic field to remove waterborne contaminants selectively bound to engineered particles. The particles are a composite of organic polymer coatings, with functional groups designed to selectively absorb contaminants, and a magnetite core. Commercially available equipment is used to remove the particles and absorb contaminants at high flow rates (up to $2400 \mathrm{gpm}$ ). The particles can be recovered and reused.

- SRL-IWT, Reverse Osmosis for Inorganic Removal Site Applicability: FHSB-GW, HLWTF-GW, LLWDF-GW Status \& Matrix ID: AV; C10

Reverse Osmosis is being investigated as a means for removal of soluble inorganic compounds from contaminated groundwater on a bench-scale level as part of a treatability study. Reverse osmosis is a process in which a solution under pressure is forced through a membrane and separates out the solvent from the solute. The advantages of this process is that it can operate at ambient temperature and the solute and solvent molecules can be similar in size. 
Matrix of Treatment Technologies

versus Waste sites

SITE

Treatment Technology Status

\begin{tabular}{|c|c|c|c|c|c|c|c|c|c|c|c|}
\hline A/CSB & ud/ip & & ud/ip & ud/ip & ud/ip & ud/ip & & & av & & \\
\hline AMGW & & & & & & & & & & & ud/ip \\
\hline AMVZ & & & & & & & & & & & ud/ip \\
\hline BRP & ud/ip & & ud/ip & ud/ip & ud/ip & ud/ip & & & av & & \\
\hline CPRB & ud/ip & & ud/ip & ud/ip & ud/ip & ud/ip & & & av & & \\
\hline FHSB & up/ip & ud/ip & ud/ip & up/ip & up/ip & up/ip & & & av & & \\
\hline FHSB-GW & & & & & & & & & & & \\
\hline FHSBSL & & & & & & & & & & & \\
\hline HLWTF-GW & & & & & & & & & & & \\
\hline HLWTF-S & & & & & & & & & & & \\
\hline LLWDF & ud/ip & ud/ip & ud/ip & ud/ip & ud/ip & ud/ip & av & & av & & \\
\hline LLWDF-GW & & & & & & & & & & & \\
\hline MLSB & ud/ip & & ud/ip & ud/ip & ud/ip & ud/ip & & & av & & \\
\hline RASB & ud/ip & & ud/ip & ud/ip & ud/ip & ud/ip & & & av & av & \\
\hline RRCP & & & & & & & & & & & \\
\hline SL-GW & & & & & & & & & & & \\
\hline SL-S & ud/ip & & ud/ip & ud/ip & ud/ip & ud/ip & & av & av & & \\
\hline SRLSB & ud/ip & & ud/ip & ud/ip & ud/ip & ud/ip & & & av & av & \\
\hline TNXSB & ud/ip & & ud/ip & ud/ip & ud/ip & ud/ip & & & av & & \\
\hline TNXGW & & & & & & & & & & & \\
\hline & A1 & A2 & A3 & A4 & A5 & A6 & A7 & A8 & A9 & A10 & A11 \\
\hline
\end{tabular}

Technology

A1 - Final Vegetation Coverage for Waste Site Closure Caps

A2 - Studies to Alter Groundwater Chemistry at Seepline

A3 - Cap Infiltration Studies

A4 - Barrier Material Test Plot

A5 - Closure Cap Barrier Materials Study

A6 - Lessons Learned from M-Area Basin Closure

A7 - Waste Stabilization via Dynamic Compaction

A8 - Waste Stabilization via Static Surcharge

A9 - Subsidence Repair of ER Closure Caps

A10 - Deep Soil Mixing and In-Situ Stabilization

A11 - In-situ Bioremediation

Legend:

ud/ip: Under Development and/or Demonstration at SRS In-Progress

av: Available, Demonstration at SRS Needed or Underway

a\&d: Available and Demonstrated at SRS 
Matrix of Treatment Technologies

versus Waste Sites, cond.

SITE

Treatment Technology Status

\begin{tabular}{|c|c|c|c|c|c|c|c|c|c|c|c|c|c|c|}
\hline A/CSB & & & & & & & & & & & & & & \\
\hline AMGW & & & a\&d & & av & av & & av & a\&d & & & & & \\
\hline AMVZ & & & a\&d & av & av & av & & & & & & & & \\
\hline BRP & & & & & & & & & & & & & & \\
\hline CPRB & & & & & & & & & & & & & & \\
\hline FHSB & ud/ip & ud/ip & & & & & & & & ud/ip & ud/ip & & & \\
\hline FHSB-GW & & ud/ip & & & & & & & & ud/ip & ud/ip & ud/ip & ud/ip & ud/ip \\
\hline FHSBSL & ud/ip & ud/ip & & & & & & & & & & & & \\
\hline HLWTF-GW & & ud/ip & & & & & & & & & & ud/ip & ud/ip & ud/ip \\
\hline HLWTF-S & & ud/ip & & & & & & & & & & & & \\
\hline LLWDF & ud/ip & ud/ip & & & & & & & & & & & & \\
\hline LLWDF-GW & & ud/ip & & & & & & & & & & ud/ip & ud/ip & ud/ip \\
\hline MLSB & & & & & & & & & & & & & & \\
\hline RASB & & & & & & & & & & & & & & \\
\hline RRCP & & & & & & & av & & & & & & & \\
\hline SL-GW & & & & & & av & & & & & & & & \\
\hline SL-S & & & & & & & & & & & & & & \\
\hline SRLSB & & & & & av & av & & av & a\&d & & & & & \\
\hline TNXSB & & & & & & & & & & & & & & \\
\hline TNXGW & & & & & av & av & & av & a\&d & & & ud/ip & & \\
\hline & B1 & B2 & B3 & B4 & C1 & C2 & C3 & C4 & C5 & C6 & C7 & C8 & C9 & C10 \\
\hline
\end{tabular}

Technology

B1 - In-Situ Mobilization of Metal Contaminants

B2 - Electrolytic Migration Technology

B3 - Horizontal Well Vapor Extraction

B4 - RF Heating Demonstration

C1 - Off-Gas Treatment for VOCs

C2 - Bioremediation Treatment for Organic Destruction

C3- Bioremediation Treatment Regime for PAH from RR Crossties

C4 - Soil Washing/Low Temperature Thermal Study

C5 - Air Stripping for VOCs - Pump and Treat Method

C6 - Re-Injection of Treated Groundwater Studies

C7 - Recovery Well and Injection Well Pump Tests

C8- Electrolytically Assisted lon Exchange for Nitrates

C9 - Seeded Magnetic Filtration for Heavy Metals

C10 - Reverse Osmosis for Inorganic Removal

Legend:

ud/ip: Under Development and/or Demonstration at SRS In-Progress

av: Available, Demonstration at SRS needed or Underway

a\&d: Available and Demonstrated at SRS 


\section{CHARACTERIZATION TECHNOLOGIES}

ERD is actively pursuing many different characterization technologies for identified waste sites at SRS. The characterization technologies have been grouped in the order of descending geographical area of applicability as given here-in.

\section{Above Surface Characterization Technologies: \\ Technologies which characterize large geographical areas from an overall perspective. Aerial photography of the site is included in this category. \\ Surface Unit Characterization Technologies: \\ Technologies which are used to characterize the uppermost levels of the ground. Ground penetrating radar is utilized to map the top layers of a site and is included in this category.}

\section{Subsurface-Unsaturated Zone Characterization Technologies: Technologies which are used to characterize the soils above the water table in the unsaturated zone. Soil gas measurements for volatile organic compounds in which a soil sample is measured is included in this category.}

\section{Subsurface-Saturated Zone Characterization Technologies: Technologies which are used to characterize the groundwater and the extent of contamination present. Modeling efforts for contaminant plume assessments are included in this category.}

A graphical representation of characterization technologies is given as Figure 2. This figure provides for a visual correlation between the technology and its application. The characterization technologies are then described per the above categories followed by a matrix of characterization technologies versus applicable waste sites. 


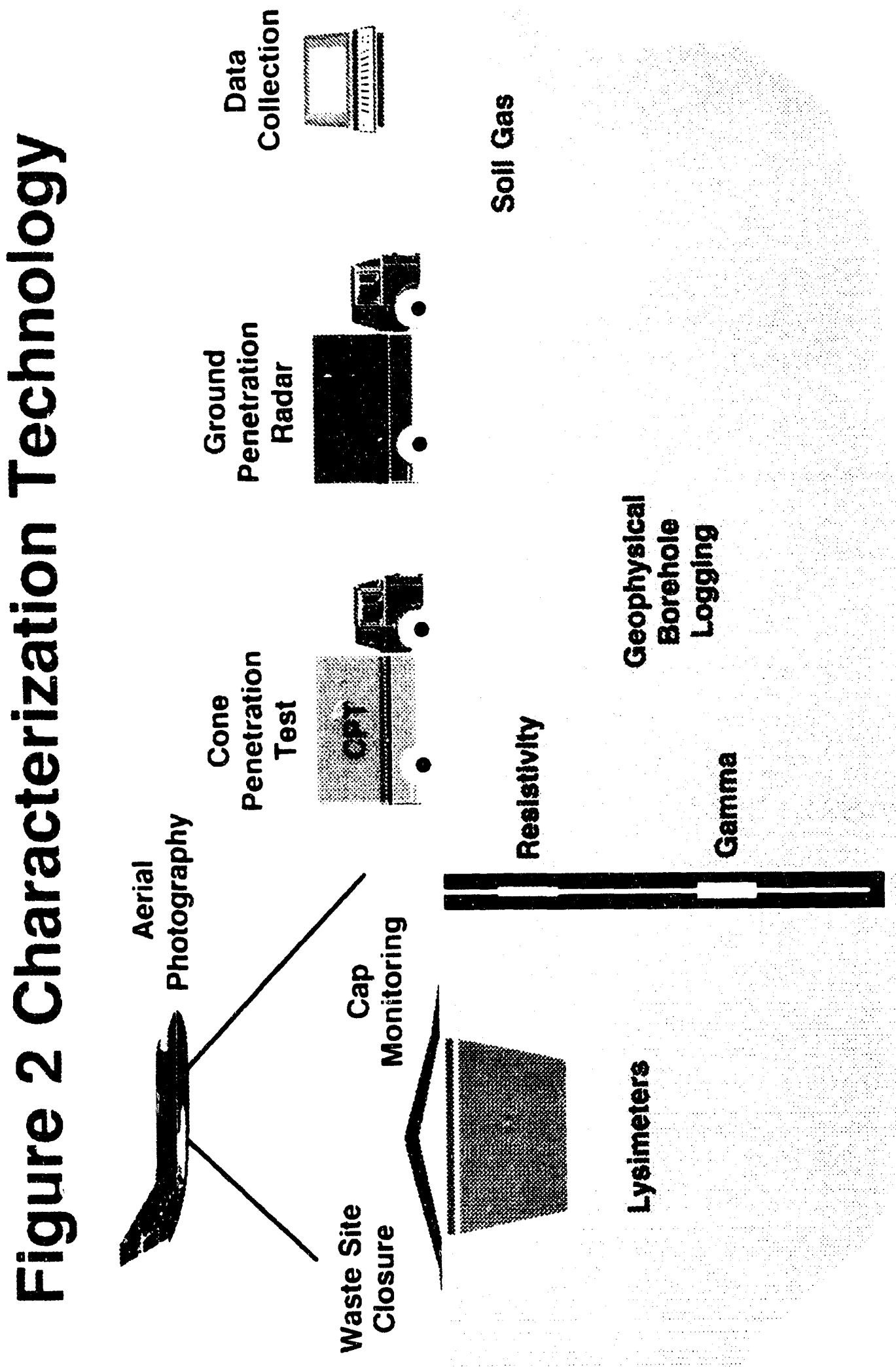




\section{ABOVE SURFACE CHARACTERIZATION TECHNOLOGIES}

- SRL-ESS, Vegetation, Fish, and Macroinvertebrate Sampling For Constituents of Concern

Site Applicability: SRLSB, Site-Wide

Status \& Matrix ID: A\&D; A1

Site specific project and regional initiatives are on-going in support of risk assessment needs at SRS. Site specific vegetation sampling and analysis has been carried out to characterize uptake and tropic level transfer of radionuclides and metals at the SRL seepage basins to support risk assessment and closure activities. These site specific data indicate that actual uptake and transfer potential is less than predicted through modeling.

Comprehensive environmental characterization of Upper Three Runs Creek (UTRC) is continuing and will provide data for use on a site specific and regional watershed basis. Characterization will include metal, volatiles, and radionuclides contaminant levels in physical media, i.e. soils, sediments, surface water and wetland water, as well as fish body burden analysis for the same constituents. Toxicity testing of UTRC water and associated wetland will also be performed. This is part of an expanding initiative by SRL and ERT to implement comprehensive environmental characterization studies on a regional basis which will support site wide risk assessment and other regulatory requirements. 


\section{ER/SRL-ESS, Aerial Photography and Photogrammetry}

Site Applicability: Site-Wide

Status \& Matrix ID: A\&D; A2

Aerial photography is being implemented to develop waste site histories for characterization efforts and to allow identification of the aerial extent of contaminant influence. This type of mapping involves infrared photography, gamma sensing, vegetation stress identification, and landsat surveys. These types of characterization efforts are being correlated with the GIS efforts to provide a site-wide data base. Also, aerial photographs are being used to generate accurate and up to date topographic maps in support of planning, characterization, and design efforts. 


\title{
SURFACE UNIT CHARACTERIZATION TECHNOLOGIES
}

\author{
ER/S\&TC, Non-Intrusive Cap Integrity Monitoring \\ Site Applicability: Any Site Closed by Capping \\ Status \& Matrix ID: UD/IP; B1 \\ The objective of this work is to develop methods and/or \\ techniques to monitor key performance parameters of \\ closures cover systems using non-intrusive methods. The \\ initial non-intrusive method being examined is the ferric \\ tagging technique. The tagging technique involves the \\ addition of ferric particles into the cap material(s) during \\ construction to provide a sensing media which can be \\ detected using penetrating electromagnetic fields to \\ monitor performance of the barrier material in the \\ closure cover system.
}

- ER, 3-D Ground Penetrating Radar

Site Applicability: LLWDF

Status \& Matrix ID: A\&D; B2

ERD supported a high resolution 2D and 3D Ground Penetrating Radar experiment performed by the Houston Advanced Research Center (HARC). This experiment was designed to study the utilization of seismic $2 \mathrm{D}$ common mid-point style data acquisition for mapping shallow geology and to evaluate the feasibility of acquiring pseudo 3D style data for mapping hazardous waste sites and "imaging" under buried waste units. The experimental report from is due in early April. HARC is a geophysical, particularly seismic, brain trust with supercomputing capability.

- SRL-ID/ADS, Ion Trap Mass Spectrophotmeter (ITMS) Site Applicability: AMVZ, SRLSB, Site-Wide Status \& Matrix ID: A\&D; B3

The ITMS has been developed as part of the OTD-ID program here at SRS. The ITMS allows for rapid field screening analysis for volatile organic compounds in soil, water, air, or mud. The utilization of this instrument will facilitate field assessments and provide for a more costeffiective sampling program. 


\title{
SUBSURFACE-UNSATURATED ZONE CHARACTERIZATION TECHNOLOGIES
}

\author{
SRL-IWT, Lysimeters to Study and Monitor \\ Radionuclide Migration in Soils \\ Site Applicability: LLWDF \\ Status \& Matrix ID: A\&D;C1 \\ Laboratory-prepared and characterized sources of \\ radionuclides can be emplaced in lysimeters to obtain \\ leaching and migration information. Both the soil in the \\ lysimeter and the source's composition can be varied to \\ obtain relative data based on parametric changes. Water \\ passing through the lysimeter may be collected and \\ analyzed to ascertain leaching/solubility information.
}

- ER, Soil Gas Measurements

Site Applicability: A/CSB, AMVR, SRLSB

Status \& Matrix ID: A\&D; C2

ERD manages 19 tasks totalling \$2.1 million for soil gas sampling as a screening technique at SRS waste sites. To date, over 5000 soil gas samples have been obtained with excellent results. Our soil gas capability includes screening for light hydrocarbons, light paraffins (C5 through $\mathrm{C} 10$ ), chlorinated solvents including Method 624 compounds, BTEX, oxygen, $\mathrm{CO} 2, \mathrm{H}, \mathrm{He}$, and mobile Mercury. EPA has complimented SRS on the use of the soil gas method and a significant savings is being realized in characterization and assessment efforts based on our soil data.

\section{SRL-ID/ESS, Cone Penetrometer Measurements Site Applicability: AMVZ, SRLSB \\ Status \& Matrix ID: A\&D; C3}

The cone penetration test is a state of the art technology, facilitating subsurface characterization of stratigraphy using a minimally invasive probe. This technology offers an inexpensive way to identify soil characteristics and parameters, while optimizing future drilling efforts. The instrumentation also allows discrete, subsurface sampling of soil and water for evaluation. 
- SRL-ESS, Geophysical Techniques (seismic, etc.) to Determine Geometry, Areal Distribution, and Age of Upland Unit at SRS

Site Applicability: Site-Wide

Status \& Matrix ID: A\&D; C4

The "Upland Unit" is the geologic unit (sediments) that occurs near surface and at the surface of the Savannah River Site. The unsaturated (dry) portion of this zone is where the contaminants move through the soil column and on into the groundwater. The purpose of this study is to characterize this geologic unit to estimate risks of contaminant migration behavior and to understand the movements of fluids through these superficial and near surface sediments. The study will provide knowledge that is applicable for the entire site region in relation to groundwater management and remediation activities.

Shallow seismic studies are also being performed on the "Upland Unit". The determination of capable faults (< 35,000 years old) is essential to reactor restart, construction of the NPR, and siting criteria for future facilities. This study will determine if this unit has been disturbed and if the Savannah River Site has capable faults.

The study will provide:

1. Modeling on the hydrologic properties of the unit.

2. Establish the existence or non-existence and capability of the faults at SRS. 
- SRL-ESS, Hg Speciation in Groundwater

Site Applicability: FHSB-GW, LLWDF-GW

Status \& Matrix ID: AV; C5

Soil samples and groundwater samples are taken and the $\mathrm{Hg}$ is analyzed for microbial activity. The $\mathrm{Hg}$ becomes methylated whereby causing the mercury to become mobile and highly toxic. These studies will tell the species of $\mathrm{Hg}$ present; either immobile, innocuous, or methylated. This is for background data and is prudent to address for future concerns.

- ER/S\&TC, Prompt Gamma Neutron Activation Analysis Site Applicability: FHSBSL

Status \& Matrix ID: AV; C6 PGNAA is a technology to be developed for a new application involving subsurface characterization. The technology will be used for continuous, in-field characterization and screening of ivaste sites at SRS, and will eliminate the need for costly and time consuming laboratory analysis. Capabilities will include use as a penetrometer to determine lithology and fluid interfaces, as a pipe crawler to characterize sewer lines and well casings, and as a probe to determine contents of underground storage tanks. 


\title{
SUBSURFACE-SATURATED ZONE CHARACTERIZATION TECHNOLOGIES
}

\author{
SRL-ESS, Modeling Efforts for Plume Assessment \\ Site Applicability: AMGW, FHSB-GW, HLWTF-GW, \\ LLWDF-GW, SL-GW, TNXGW \\ Status \& Matrix ID: A\&D; D1 \\ Modeling of groundwater flow and contaminant \\ movement has been performed to support site \\ characterization, RCRA, ACL demonstrations, CERCLA \\ remedial alternative risk assessments, and evaluation \\ and design for hydrologic control and capture of \\ contaminants. Groundwater modelling is being used in \\ the design and evaluation of $\mathrm{A} / \mathrm{M}$ area recovery well \\ system, the F\&H seepage basin recovery and injection \\ well system, and for the ACL demonstration for Mixed \\ Waste Management Facility, Sanitary Landfill Facility, \\ and the $\mathrm{A} / \mathrm{M}$ Southern Sector.
}

\section{SRL-ESS, Stochastic Inverse Contaminant Flow and Transport Modeling}

Site Applicability: AMGW, FHSB-GW, HLWTF-GW, LLWDF-GW, SL-GW, TNXGW

Status \& Matrix ID: UD/IP; D2

This task will improve groundwater modeling by constraining the possible hydraulic conductivities that can be used in a model by considering an existing contaminant distribution as well as observed heads. The stochastic portion of the program should enhance monitoring programs by guiding the selection of monitoring wells such that reduction in uncertainty is maximized. 
SRL-ESS. Tritium Dating of Aquifers to Determine Waste Water Penetration Depth

Site Applicability: AMGW

Status \& Matrix ID: A\&D; D3

The advent of nuclear testing and production of tritium at SRS has tagged the rainwater with elevated tritium levels. The tritium concentration level identifies the approximate ages of the groundwater because it is possible to distinguish between pre-nuclear age and postnuclear age tritium. Through this information it is possible to determine the depth of discharge water penetration to aquifers.

SRL-ID/ESS/USGS, DNAPL Characterization and Assessment

Site Applicability: AMVZ

Status \& Matrix ID: UD/IP; D4

The characterization of a dense non-aqueous phase liquid (DNAPL) known to exist at SRS is being done through innovative technologies using existing well data and hydrogeologic information. The non-aqueous phase is known to be trichloroethylene and tetrachloroethylene trapped in various subsurface features and the organics when in contact with the PVC well casings will cause swelling and deformation of the PVC. Two techniques are being utilized to determine the existence of well casing deformation. Geophysical logging and caliper logging will be utilized down existing wells and will be capable of detecting deformation of the PVC casing. The use of gamma-gamma and natural gamma logging will also be use $\mathbb{f}$ to analyze soil densities. 
Matrix of Characterization Technologies

versus Waste Sites

SITE

Characterization Technology Status

\begin{tabular}{|c|c|c|c|c|c|c|c|c|c|c|c|c|c|c|c|}
\hline A/CSB & & a\&d & ud/ip & & & & a\&d & & & & & & & & ud/ip \\
\hline AMGW & & & & & & & & & a\&d & & & & ud/ip & a\&d & \\
\hline AMVZ & & & & & a\&d & & a\&d & a\&d & & & & & & & \\
\hline BRP & & a\&d & ud/ip & & & & & & & & & & & & \\
\hline CPRB & & a\&d & ud/ip & & & & & & & & & & & & \\
\hline FHSB & & a\&d & ud/ip & & & & & & & & & & & & \\
\hline FHSB-GW & & & & & & & & & a\&d & av & & & ud/ip & & \\
\hline FHSBSL & & a\&d & & & & & & & & & av & & & & \\
\hline HLWTF-GW & & & & & & & & & & & & a\&d & ud/ip & & \\
\hline HLWTF-S & & a\&d & & & & & & & & & & & & & \\
\hline LLWDF & & a\&d & ud/ip & a\&d & & a\&d & & & & & & & & & \\
\hline LLWDF-GW & & & & & & & & & a\&d & av & & & ud/ip & & \\
\hline MLSB & & a\&d & ud/ip & & & & & & & & & & & & \\
\hline RASB & & a\&d & ud/ip & & & & & & & & & & & & \\
\hline RRCP & & a\&d & & & & & & & & & & & & & \\
\hline SL-GW & & & & & & & & & a\&d & & & a\&d & ud/ip & & \\
\hline SL-S & & a\&d & ud/ip & & & & & & & & & & & & \\
\hline SRLSB & a\&d & a\&d & ud/ip & & a\&d & & a\&d & a\&d & & & & & & & \\
\hline TNXSB & & a\&d & ud/ip & & & & & & & & & & & & \\
\hline TNXGW & & & & & & & & & a\&d & & & & ud/ip & & \\
\hline
\end{tabular}

Technology

A1 - Vegetation, Fish, and Macroinvertebrate Sampling

A2 - Aerial Photography and Photogrammetry

B1 - Non-Intrusive Cap Integrity Monitoring

B2 - 3-D Ground Penetration Radar

B3 - Ion Trap Mass Spectrophotometer

C1 - Lysimeters to Study and Monitor Radionuclide Migration in Soils

C2 - Soil Gas Measurements

C3 - Cone Penetrometer Measurements

C4 - Geophysical Techniques

$\mathrm{C} 5$ - $\mathrm{Hg}$ Speciation in Groundwater

C6 - Prompt Gamma Neutron Activation Analysis

D1 - Modeling Efforts for Plume Assessment

D2 - Stochastic Inverse Contaminant Flow and Transport Modeling

D3 - Tritium Dating of Aquifers to Determine Waste Water Penetration Depth

D4 - Measurements for DNAPL Assessment

Legend:

ud/ip: Under Development and/or Demonstration at SRS In-Progress

av: Available, Demonstration at SRS Needed or Underway

a\&d: Available and Demonstrated at SRS 


\section{ENVIRONMENTAL RESTORATION TECHNOLOGY FUTURE ROLE}

As discussed in the overview of treatment and characterization technologies, WSRC-ER has a number of new technology initiatives underway which should should yield information and experience useful to ER in accomplishing its objectives. WSRC-ER is developing plans for a Technology Steering Committee to review new technology proposals for future funding. In addition, WSRC-ER has begun developing strategic plans for providing technology support for the large amount of RI/FS work to be initiated in FY93 and beyond.

Interfaces with customers and suppliers on technology transfer and information exhange are constantly evolving. SRTC was recently reorganized, and renamed, in response to the changing mission of the site from a Defense Programs role to one of Waste Management and Environmental Restoration. Organizational changes within SRTC streamlined ER support. The cross-linking of applicable DOE-OTD technologies with ER needs as identified by the EM-40 Technology Needs Assessment (TNA) will continue to be pursued. The TNA will be updated as required with the latest revision now underway. The cross-linking process will also be accomplished at the same time. Future efforts will focus on a joint effort with SRL-ESS/ID personnel to identify other DOE ID activities applicable to SRS remediation projects.

WSRC-ERs relationship with Westinghouse Corporate is growing with their recent addition to the Westinghouse Technology Council. Interfaces with other Divisions is being facilitated through the bi-monthly S\&TC Waste and Environmental Information Exchange forums. Technology transfer terms and the mechanism for accessing the other Corporate Divisions continues to be clarified. The Westinghouse GOCO Environmental Committee recently held its first-ever senior environmental managers interface meeting with Martin Marietta Energy Systems (MMES) in Oak Ridge to share information on their respective programs.

Savannah River and Oak Ridge plan to continue their quarterly ER Technical Information Exchanges. The need for a complex-wide ER technical information exchange forum is also being studied. 


\section{ACKNOWLEDGEMENTS}

The authors wish to acknowledge the following professionals for their contributions to this report.
S. R. McMullin, ERT
R. D. Baena, ERT
H. P. Holcomb, ERT
S. T. McKillip, ERT
W. W. Pidcoe, ERT
S. L. Rhodes, ERT
M. G. Serrato, ERT
A. P. Spencer, ERT
C. F. Von Lang, ERT
L. Voss, ERT
M. Welty, ERT
D. E. Wyatt, ERT 

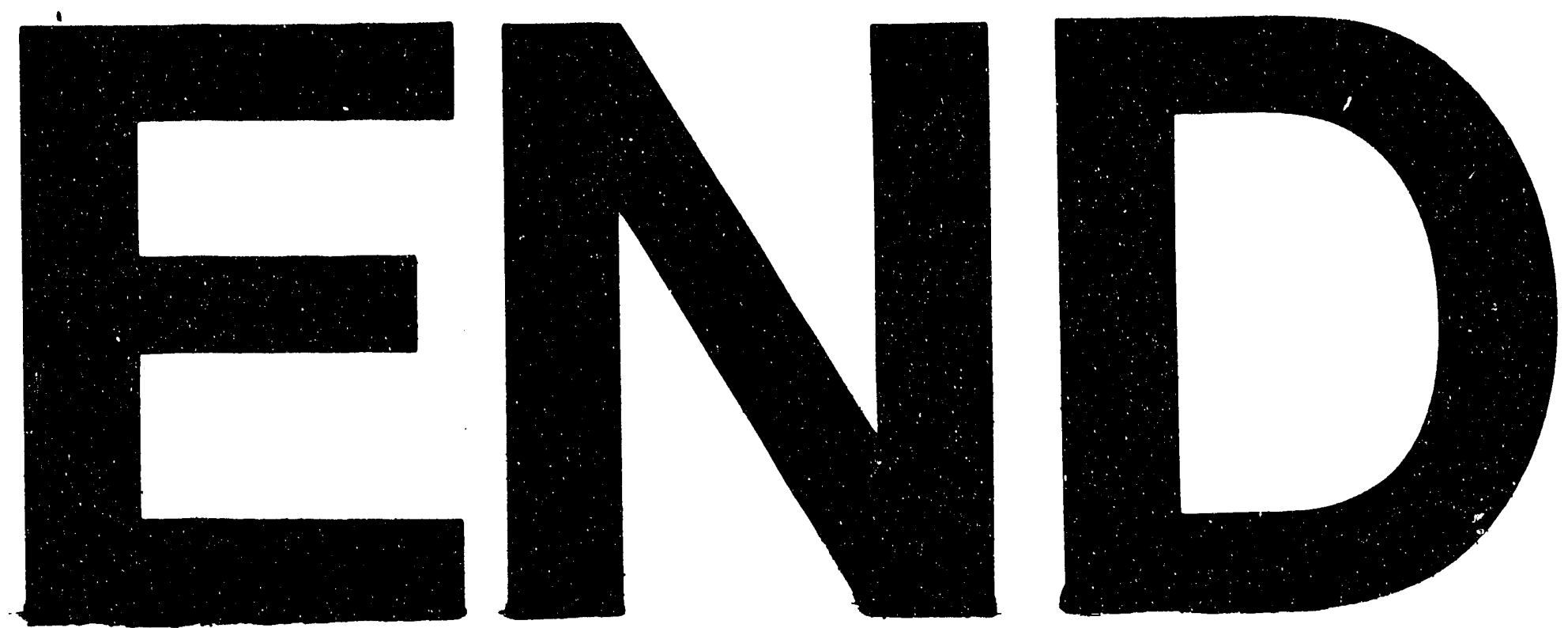

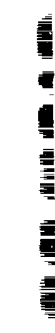
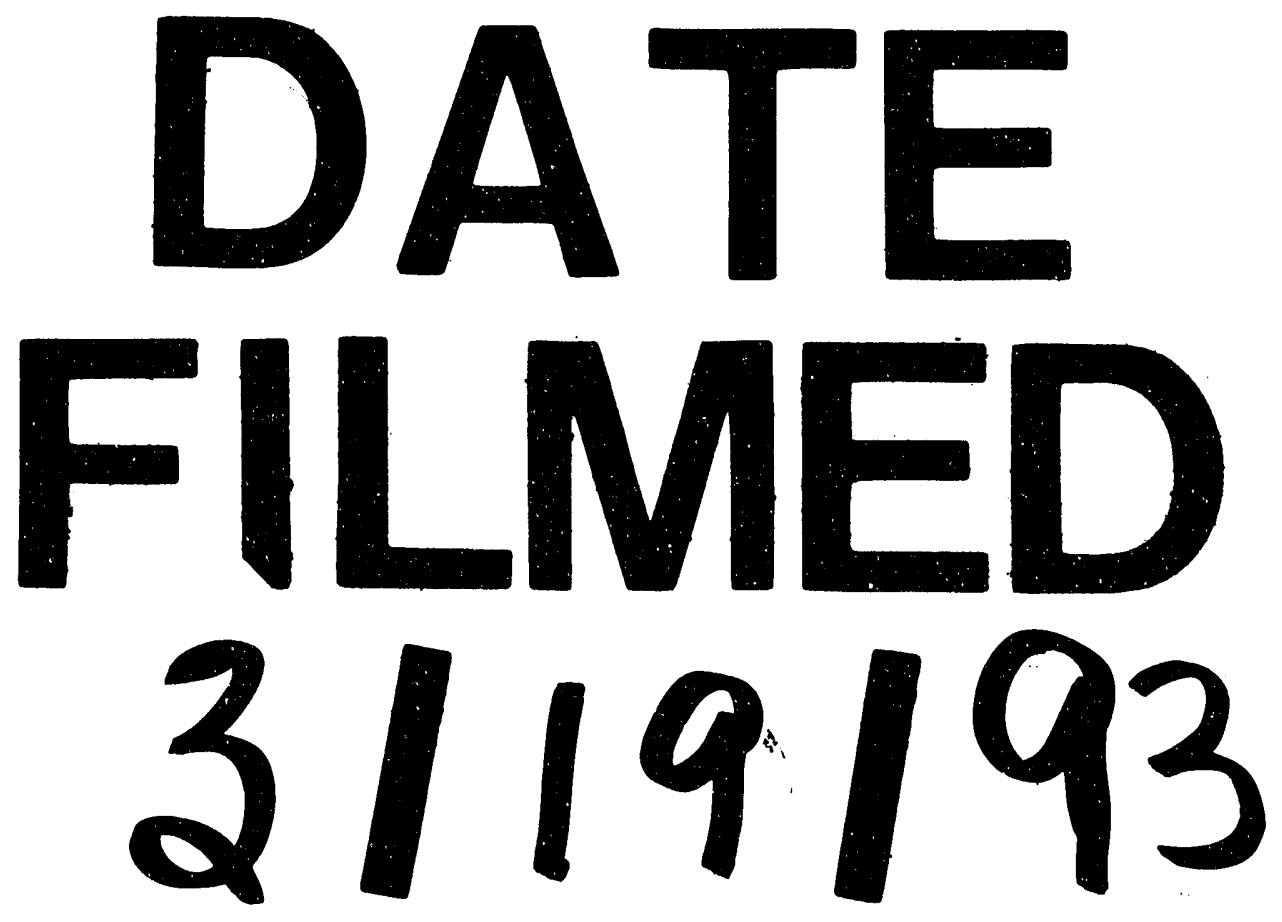
